\title{
Preface $^{1}$
}

This book emerged from the author's engagement (the nature of which is reflected in my publications listed in the Bibliography) with constitutional comparison. The explosive surge of comparative activity in the context of public (especially constitutional) law must no doubt be ascribed, at least partially, to the phenomenon often hazily referred to as 'globalization'. Markers of globalization such as the mobility of humanity across borders, hitherto unprecedented in history, have perceptible, though sometimes opaque, consequences for our understanding of the contemporary state, its powers, responsibilities and foundations. One of these consequences is the increasing prevalence of religious pluralism in the populations of most states of the $21^{\text {st }}$ Century. Another indicator of globalization is the deepening penetration of constitutional language emerging from the history of the state in the 'Western' world into the global vernacular. A prominent example of this is the notion of 'constitutionalism', which is widely used as a cipher for a desirable state of affairs in any country, but whose meaning is vague, at least around its edges.

To broach, as is the present intention, the theme of an appropriate response for the constitutional state to the difficulties arising from religious pluralism without providing an outline of the meaning in which key concepts such as 'religion', 'globalization', 'constitutional comparison' and especially 'constitutionalism' are used, would be futile. Simply using homonymic constitutional terminology without clarifying one's choice of meaning (incidentally a phenomenon that occurs too often in constitutional writing) is to contribute to confusion rather than elucidation. Therefore, the earlier chapters of this book are dedicated to outline and solidify the conceptual context within which the theme is addressed in the later parts.

Formulating uncontested definitions for constitutional notions and producing unopposed solutions to legal problems will always be an

1 Venter, F., 2015, Constitutionalism and Religion, Edward Elgar, Cheltenham, was accepted for publication following a double-blind peer review process conducted by the Publisher. 
unreachable objective. However, definition and solution are essential components of the lifeblood of legal scholarship, because they create a framework for the discussion, disputation and production of answers to intractable questions. In the final chapter lines drawn from the preceding delineation of the meaning of key concepts, comparative analyses of current practice, and the interpretation of global trends regarding the state and religion, are drawn together. The result is a suggestion for the direction in which constitutional states may seek an improved approach to religious pluralism in the interests of justice. It is hoped that the suggestion merits consideration on the agenda of constitutionalism and that its discussion among readers will bring about its further refinement.

The regional or local perspective from which constitutional comparison is undertaken can determine its nature and goals. More often than not, comparatists seek to strengthen their arguments for the improvement of their home legal order by means of their description and analysis of comparative materials. Such is a legitimate approach, but not one that is followed here. The themes and questions addressed here so penetrate the realities prevalent in so many jurisdictions that the comparative perspective is not one specifically focused on the author's native environment (South Africa). Globalization has indeed caused constitutionalism and religious pluralism to be universal phenomena calling for intensive consideration and improved solutions to the problems generated thereby in all jurisdictions.

I am grateful to Edward Elgar Publishing for the professional processing of the manuscript, including its expeditious submission to rigorous prior peer review. I have benefited much from the comments of the three reviewers that were provided to me anonymously by the publisher before finally submitting the text for publication.

The research necessary for the writing of this book was made possible by the financial support generously made available by the Alexander von Humboldt Foundation, the Max Planck Society and the National Research Foundation. The opinions, findings and conclusions reflected here are however exclusively those of the author and therefore do not in any way bind or commit any of the funding institutions.

This book is dedicated to my children and grandchildren with the wish that their lives will not be blemished by secular neutrality.

Francois Venter

North-West University

Potchefstroom

March 2015 